\begin{tabular}{rr} 
çağdaş & Yaratıcı Drama Dergisi 2018, 13(1), 85-100 \\
drama & www.yader.org \\
\hline
\end{tabular}

\title{
Yaratıcı Drama Yöntemiyle Farklı Kültürleri Tanıma ve Bir Arada Yaşama Çalışmaları
}

\author{
Tuba Çay Sağlam ${ }^{1}$ \\ Nami Eren Beștepe ${ }^{2}$
}

\begin{tabular}{|c|c|c|}
\hline \multicolumn{2}{|c|}{ Makale Bilgisi } & Öz \\
\hline \multicolumn{2}{|c|}{ DOI: $10.21612 /$ yader.2018.006 } & $\begin{array}{l}\text { Insanin insan olarak varlı̆̆ın sürdürmesinin birç̧ok düşünürce olmazsa olmazı sayılan toplum } \\
\text { yaşamı, artık çok kültü̈rlülükle yaşayabilme becerisi geliştirmeyi gerektiriyor. Bu durum da dünya }\end{array}$ \\
\hline \multicolumn{2}{|c|}{ Makale Geçmişi } & üzerindeki farkl kültürleri tanımayl gerekli kallyor. İnsanın gelişim süreci düşünüldü̈ğünde, soyut \\
\hline Geliş tarihi & 26.11 .2017 & 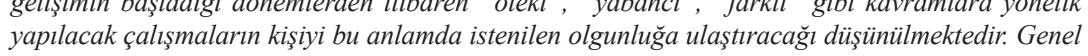 \\
\hline \multirow[t]{2}{*}{ Kabul } & 11.1.2018 & $\begin{array}{l}\text { olarak, çalışmaya katılan çocukların dünya üzerinde yaşayan farklı kültürleri yaratıcı drama } \\
\text { yöntemiyle tanımaları amaçlanmıştır. Çalışma grubu, ilkokul ögrencisi olan, yedisi yedi yaşında, } \\
\text { beşi sekiz yaşında olan ve daha önce drama yaşantısı olmayan toplam on iki çocuktan oluşmuştur. }\end{array}$ \\
\hline & & Araştırma, temel yorumlayıcı nitel bir çalışmadır. Araştırmada gerçekleştirilen uygulamalar \\
\hline \multicolumn{2}{|c|}{ Anahtar Sözcükler } & yaratıcı drama yöntemiyle yapılandırllmış olup, sekiz oturumda toplam yirmi saatlik atölye \\
\hline \multicolumn{2}{|c|}{ Yaratıcı drama } & $\begin{array}{l}\text { gerçekleştirilmiştir. Araştırma kapsamında ulaşılan veriler odak grup görüşmesi aracıllı̆̆yla } \\
\text { elde edilmiştir. Araştırmanın amacı doğrultusunda hazırlanan on üç tane açı uçlu soru ilk }\end{array}$ \\
\hline \multicolumn{2}{|c|}{ Çok kültürlülük } & oturum öncesi ve son oturumun bitiminden sonra gruba yöneltilmiştir. Araştırmada elde edilen \\
\hline \multicolumn{2}{|c|}{ Birlikte yaşama becerisi } & $\begin{array}{l}\text { verilerin çözümlenmesinde betimsel analiz tekniği kullanılmıștır. Verilerin betimsel analizi, } \\
\text { "Farklıllklar", "Farkl kültürler", "İnsanın degerli oluşu" ve "Farkll kültürden olanla işbirliği }\end{array}$ \\
\hline \multicolumn{2}{|c|}{ Farklı kültürleri tanıma } & $\begin{array}{l}\text { ve birlikte yaşayabilme" temaları çerçevesinde değerlendirilmiştir. Araştırmanın sonunda, } \\
\text { çocukların, her insanı, insan olmasından dolayı değerli bulduklarl, çocukların farklı olanı } \\
\text { "öteki" olmaktan çıkardıkları, kültürlere karşı ilgi duydukları, bilgi edinmek istedikleri, beraber } \\
\text { de yaşanabileceğine ilişkin olumlu düşünceler gelişstirdikleri ve karşı tarafin gereksinim, ilgi ve } \\
\text { isteklerini de göz önüne alarak düzenleme vaptıkları ve vapabilecekleri sonucuna varılmıstır. }\end{array}$ \\
\hline
\end{tabular}

\begin{tabular}{c}
\hline Works of Living Together and Recognizing Different Cultures \\
through Creative Drama Method
\end{tabular}

\begin{tabular}{l} 
Article Info \\
\hline DOI: $10.21612 /$ yader.2018.006
\end{tabular}

\section{Article History}

Received $\quad 26.11 .2017$

Accepted $\quad 11.1 .2018$

\section{Keywords \\ Creative drama \\ Multiculturalism \\ Skill to live together \\ Recognizing different cultures} \begin{abstract}
Works of maintaining communal life and public life, which is considered a must by many thinkers for a human being to sustain his existence as a human, now require one to develop a skill of living with multiculturalism. When development process of men taken into consideration, it has been considered that works to be conducted on topics such as "the other", "stranger", and "different" would get one into the desired maturity in this sense since abstract development began. Generally, questions to be answered in the research in which the aim is to enable students who participated in the work to recognize different cultures in the world through creative drama method are: What are children's views related to the existence of different cultures? What are children's views on differences? What are children's views on human beings'value(s) that stem from being a human? What are children's views on cooperating and living together with the ones from different cultures? Study group consists of 7 seven-year-olds and 5 eight-year-olds, with a total number of twelve, who did not have drama experience before.
\end{abstract}

The research is a basic interpreting qualitative work. The applications realized in the research were structured with creative drama method, and a total of twenty hours of workshop was conducted in eight sessions. Data gathered in the research content were obtained by focus group interview. Thirteen open-ended questions prepared in light of the research's aim were asked to the group before the first session and at the end of last session. Descriptive analysis technique was used in analyzing the data obtained in the research. Descriptive analysis of the data was evaluated within themes such as "Differences", "Different cultures", "Having humanistic value" and "Cooperating and living together with the ones from different cultures". At the end of the research, it was concluded that the children found all people valuable since they were humans, that the children excluded "the other" what is different, that children were interested in cultures and wanted to get knowledge, that they developed positive thoughts on living together and that the children organized and would be able to organize by taking the opposing side's needs, interests and desires into consideration. 


\section{Giriş}

Günümüzde farklı kültürlerin bir arada yaşama, eğitim alma, çeşitli ortamları paylaşma gibi nesnel bir gerçekliği var. İnsanın insan olmasından kaynaklı oluşturduğu bu anlam dünyasının önemini yeniden insana kavratmak için sistemli bir biçimde eğitimle yoğrulması gerekiyor.

Çok kültürlülük ve küreselleşmenin yaygınlaştığı bu yüzyılda, beraber yaşanılan/yaşanmaya çalışılan diğer kültürün “öteki” olarak görülmesi nedeniyle iletişim ve ilişki sorunları sıkça görülen bir durum halini almaya başladı. Kültür ve çok kültürlülükle ilgili bu konular konuşulurken kültürden ne anlaşıldığına da kısaca bakmak gerekir. Kültürle ilgili farklı tanımlar vardır. Bunlardan biri Türk Dil Kurumu Büyük Sözlüğünde (www.tdk.gov.tr) şöyledir: “Tarihsel toplumsal gelişme süreci içinde yaratılan bütün maddi ve manevi değerler ile bunları yaratmada, sonraki nesillere iletmede kullanılan, insanın doğal ve toplumsal çevresine egemenliğinin ölçüsünü gösteren araçların bütünü, hars, ekin.” Bir başka tanıma bakarsak; kültür, varsayılan hedefler, arzular, ihtiyaçlar ve kapsayıcı değerler gibi jenerik beklentilerin kaynağıdır (Kitayama, Duffy, Kawamura, Larsen, 2003). Kültür ve toplum kavramları birbirleriyle ilişkili kavramlardır. Hiçbir toplum kültür olmadan var olamayacağ1 gibi hiçbir kültür de toplum olmadan var olamaz (Giddens, 2000). Bu konu özellikle bazı sosyologlarca o denli önemsenmiştir ki kültürün olmadığı yerde bilinen manada insan bile olunamayacağı ileri sürülmüştür (Giddens, 2000).

Kültürlerarası iletişim, kişilerin kendi kültürleriyle beraber diğer kültürleri tanımaları ve süreçte tutum, bilgi ve becerilerini geliştirmeyi amaçlar ki bu da hoşgörü ve saygıyı artırır (İlhan, 2010, s.19). Bu iletişim doğru olarak kurulmadığında "yabancı" kavramını fazlaca vurgulanır hale gelebilir. Aslında tarih boyunca bir "öteki” hep olmuştur. İnsanlar, toplumlar bir şekilde ilişkilerini ve hayatlarını sürdürürken ötekini yanlarında taşımışlardır. "Öteki” sözü her zaman dolaylı olarak "kendi” sözünü içerir (Öğretmen Yetiştirme ve Hizmet içi Eğitiminde Kültürlerarası Öğrenme için Avrupa Modüler Programı (ilkokul Pedagojisi) Projesi, 2006). Connolly’e (1995, s.92-93) göre, "Kimlik var olmak için farklılığa gereksinim duyar ve kendi kesinliğini güven altına almak için farklılığı ötekiliğe dönüştürür.”. Kimlik ötekiler yoluyla, onların varlığıyla şekillenmekte, tanımlanmaktadır (Uluç ve Boz, 2015).

İlk çağlardan beri düşünürlerse insanın yaşadığı toplumla bir bütün olduğu vurgusu yapılmaktadır. Üskül'e (2003) göre, toplum bireylerden oluşur ama bütün, doğal olarak parçalardan önce gelir. İnsan kendi kendine yeterli olmayan ve yaşamak için benzerlerine gereksinim duyan, mutlu olabileceği eylemleri bir toplum içerisinde gerçekleştiren bir varlıktır. Toplumlar ise daha çeşitli, daha renkli ve farklı unsurları yapılarında bulundurma yolunda ilerlemektedirler. Günümüzde toplumların yapısının tek kültürlülükten çok kültürlülüğe evrildiği düşünülürse çalışmanın yeri daha netleşecektir. Toplumsal yaşamı devam ettirme çalışmaları ve insanın insan olarak varlı̆̆ını sürdürmesinin birçok düşünürce olmazsa olmazı sayılan toplum yaşamı çok kültürlülükle yaşayabilme becerisi geliştirmeyi gerektiriyor artık. Uzun vadede düşünüldüğünde sistematik olmasa da soyut gelişimin başladığı dönemlerden itibaren "öteki”, "yabancı", "farklı" gibi konularda yapılacak çalışmaların kişiyi bu anlamda istenilen olgunluğa ulaştıracağı düşünülmektedir. Kişi farklı farklı kültürleri tanıdıkça, her kültürdeki yaşayış, gelenek-görenek ve inanışları gözledikçe benzer ve hatta aynı noktaları keşfeder ve kendi kültürünün dışındaki kültürleri ötekileştirmekten uzak durabilir ve önyargı geliştirmez. 
Toplum ve birey arasında sürekli devam eden çember şeklindeki ilişki düşünülürse değişen bireyin toplumu; değişen toplumun da bireyi etkileyeceği söylenebilir. Toplumların değişip bireyi olumlu yönde etkilemesi için de yine bireyin doğru başlangıç noktası olduğu düşünülebilir. Bu nedenle ki gruplar halinde çalışılan ve bireylerin yaşantılarından, gözlemlerinden, dolgunluklarından, bilgi, istek, hayallerinden yola çıkan ve bireyin aktif katılımcı, üretici olduğu yaratıcı drama çalışmasının konuyu istenilen noktaya taşıyabileceği düşünülmektedir.

Yaratıcı drama "bir grubu oluşturan üyelerin yaşam deneyimlerinden yola çıkarak, bir amacın, düşüncenin, doğaçlama, rol oynama (rol alma) vd. tekniklerden yararlanarak canlandırılmasıdır” (Adıgüzel, 2013, s.45). Yaratıcı drama çalışmalarındaki sürekli etkileşim çalışma boyunca ve çalışma sonrası farklı düşünceleri bir arada görme ve gerektiğinde uzlaştırma ya da ayrıştırma olanağ1 sağlar. Günümüzde kavram karmaşasından doğan birçok yaşantısal ve düşünsel sorun bu şekilde birçok farklı çözüm yoluna kavuşabilir. Hatta bu çözüm yollarının denenmesine olanak sağlayabilir. Yaratıcı drama çalışmaları aynı zamanda araştırma yeteneğini de geliştirerek keşfederek öğrenme olanağı sağlar. Yaratıcı dramada doğaçlama ile öğrenciler sosyal beceriler inşa edebilir, daha duyarlı dinleyicilere dönüşebilir, daha uygun ve olgun konuşmacılar olabilirler. Gelişen bu becerilerinin de günümüzde yetişkinlerin bile ele almaya çekindiği değer ve insan sorunlarına karşı daha uzlaşmacı, kabul edici, empatik tutumların çocuklarca gösterilebileceği düşünülebilir.

Yaratıcı dramanın uygulanış biçimiyle ilintili olarak katılımcıya sağladığı bağımsız düşünebilme, kendine güven duyma ve karar verme becerisi, felsefi düşünme boyutu kazanmış bireyler için, dolayısıyla sağlıklı toplumlar için olmazsa olmaz bir yapı taşıdır. Dolayısıyla çalışmada beklenilen farklı kültürleri tanıma ve bir arada yaşamaya adım atma becerileri için uygun eğitim yönteminin yaratıcı drama olduğu söylenebilir.

Yaratıcı dramanın bireye kazandırdığı farklı olay, olgu ve durumlarla ilgili deneyim kazanma, olaya, duruma göre tavır alma, olay/durumun birçok bakış açısı ile değerlendirilmesi ve kavramları somutlaştırma gücü böylesi bir eğitim açısından oldukça faydalıdır. Çocuk gelişiminde belirli sözel becerilerin referansıyla yaratıcı drama yaratıcı kapasitenin olgunlaşma ve gelişimini desteklemektedir (Stern, 1983).

Yaratıcı drama çalışmalarında sonuç değil sürecin temel alınması, katılımcının hata yapma korkusunu geri plana itmekte, bu da özgürce fikirlerini söylemesine, aşağılanma, dışlanma gibi toplumsal kaygılarını en aza indirerek kendisi farklı olay ve durumlar içinde farklı rol ve ilişkilerde deneyerek gerçek hayata hazırlamaktadır. Empati becerilerini de geliştirecek olan bu uygulamalarla farklı kalıpların denenmesinde deneme yanılma olanağı veren drama çalışmaları kişiyi izleyici olmaktan çıkarıp aktifleştirir. Kişi farklı olandan ve farklı olmaktan korkmadan üretir. Bireyin böylece farklı kültürden insanların yaşamlarını, kültürlerini, düşünce yapılarını hem izlediği hem de "o" olarak yaşadığı ve hatta hissettiği söylenebilir. Bu sayede, elde edilen bilgi, izlenim, kavram, her canlandırmada, her izlemede yeniden birçok farklı alternatifle kişinin zihnine yerleşebilir. Bu da gerçek yaşamda çok yönlü düşünebilen, sorun değil çözüm odaklı, uzlaşmacı, yapıcı, empati kurabilen, sorgulayan, araştıran, ön yargılarından sıyrılmış bireylerin yetişmesine katkı sağlar.

Farklı1ıkları fark etmek kabul için ilk adımdır (Tuğrul, 2006; Isenberg ve Jalongo, 2001). "Farklı olmak" kavramının zihinlerde ilk çağrıştırdığı anlam; kural dışı olmak, uyumsuzluk, çatışma vb. negatif duygu ve düşünceler olsa da "farklı olmak" aslında bu negatif algılarla baş edebilecek kadar yüksek özgüven ve kararlılık ifadesi içermektedir (Tuğrul, 2006). Bu ilk çağrışımlarla baş 
etmek, önyargıları kırmak, ancak kişinin empati kurması, çift yönlü düşünmesi, sorgulaması ve araştırmasıyla mümkündür. $\mathrm{Bu}$ anlamda drama insanları birbirine bağlayabilir, öğrenme ortamını iş birliğine çevirebilir ve yaratıcılık, eleştirel sorgulama ve ifade için yeni ifade alanları oluşturabilir (Van de Water, McAvoy ve Hunt, 2015).

Çocuklar için düşünmek eğlenceli bir süreçtir; çünkü çocuklar düşünceleriyle oynarlar (Tuğrul, 2006). Düşünmeyi zevkli kılan sadece bize tattırdığı özgürlük duygusu değil, aynı zamanda bir şeyi yakalama, keşfetme heyecanıdır (Tuğrul, 2006; Vasniadou, 2004; Wood 1999). Çalışmanın yapıldığı yaş grubu keşfetme, araştırma, merak duygularının diri olduğu dönemdir. En iyi filozofların çocuklar olduğu biraz da mecaz yüklü bir ifade ile sıklıkla halk tarafından kullanılır. Bu ifade aslında, toplumsal korku ve baskıların içine tam anlamıyla henüz girmemiş, aklına geleni en yalın haliyle soran ve öğrenmek isteyen çocuklar düşünüldüğünde doğru kullanılıyormuş gibi görünüyor. Çalışmanın yaratıcı drama ile planlanmasının çocukların içine girdikleri yabancı hissetmeyecekleri bir atmosferle belki de ilk defa duyacakları ya da pek de aşina olmadıkları kavramları daha rahat bileşenlerine ayırabilecekleri, çekinmeden eleştirebilecekleri ve bu konudaki olumlu/olumsuz alternatif düşünme biçimlerini destekleyici rol oynayacağı düşünülmektedir.

Kavramların, inanışların, değer yargılarının birçoğunun temellerinin çocukluk döneminde atıldığg ve zor değiştiği düşünülürse tersi davranış kalıplarının temellerinin de yine çocuklukta yapılacak çalışmalarla atılabileceği söylenebilir. Kültür, farklı kültür, değer verme, bir arada yaşama, iş birliği yapma, empati kurma, insanın değeri gibi bir ucu soyut düşünmenin tam da ortası diyebileceğimiz konulardır. Bu yaş grubunun bu konuları, merakla karşılayacağı, ilgisini çekeceği, öğrenmek isteyeceği ve kısa sürece içselleştireceği düşünülmektedir.

\section{Çalışmanın Amacı}

Temelde çocukların farklı kültür-yaşayışlarıyla kendi kültürü-yaşayışı arasında benzerlik ve farklılıkları yaşantılarla belirleyebileceği düşünülebilir. Toplumlarda farklı olanı öteki olarak görme ve dışlama davranışlarının altında yatan nedenlerden olan ötekinden korkma duygusunun "tanıma" ile aza indirilebileceği söylenebilir. Bu bağlamda, çalışmada genel olarak, çalışmaya katılan çocukların dünya üzerinde yaşayan farklı kültürleri yaratıcı drama yöntemiyle tanımaları amaçlanmıştır.

Bu genel amaç doğrultusunda aşağıdaki sorulara yanıt bulunmaya çalışılmıştır.

1. Çocukların farklı kültürlerin varlığına ilişkin görüşleri nelerdir?

2. Çocukların farklılıklara ilişkin görüşleri nelerdir?

3. Çocukların insanın insan olmaktan kaynaklanan değerine/değerlerine ilişkin görüşleri nelerdir?

4. Çocukların farklı kültürden olanlarla işbirliği ve birlikte yaşayabilme konusundaki görüşleri nelerdir?

\section{Yöntem}

\section{Araştırmanın Modeli}

Çocukların, dünya üzerinde yaşayan farklı kültürleri yaratıcı drama yöntemiyle tanımaları amaçlanan araştırma, nitel araştırma yöntemine dayalı bir araştırmadır. Nitel araştırma; gözlem, görüşme ve doküman analizi gibi nitel veri toplama yöntemlerinin kullanıldı̆̆ı, algıların ve olayların 
doğal ortamda gerçekçi ve bütüncül bir biçimde ortaya konmasına yönelik nitel bir sürecin izlendiği araştırmadır (Yıldırım ve Şimşek, 2006).

\section{Çalışma Grubu}

Çalışma grubu Adana ili Çukurova ve Seyhan ilçelerine yapılan duyurular sonucu gönüllü çocuklardan oluşmuştur. Yedisi yedi yaşında, beşi sekiz yaşında olan ve daha önce drama yaşantısı olmayan toplam on iki çocuk çalışma grubunu oluşturmaktadır. Bu yaşlar somut düşünce kalıplarının yerlerini yavaş yavaş soyut kalıplara bıraktı̆̆ı, soyut kavramların büyük bir hızla merak edilerek öğrenilmek istenen yaş grubudur. Çalışmanın çocukları temel alarak planlanması ise çocukların sürekli değişen, gelişen zihin ve ruhsal yapılarının toplumun temeli de olması nedeniyle anlamlıdır.

\section{Verilerin Toplanması ve Analizi}

Araştırma kapsamında ulaşılan veriler odak grup görüşmesi aracılığıyla elde edilmiştir. Odak grup görüşmesi "1lımlı ve tehditkar olmayan bir ortamda önceden belirlenmiş bir konu hakkında algıları elde etmek amacıyla dikkatle planlanmış bir tartışmalar serisi”" olarak tanımlanabilir (Yıldırım ve Şimşek, 2006). Araştırmanın amacı doğrultusunda on üç tane açık uçlu soru hazırlanmıştır. Bu on üç soru, ilk oturumun başlangıcında ve son oturumun bitiminden sonra gruba yöneltilmiş ve elde edilen veriler bilgisayar ortamına aktarılarak derlenmiş araştırma soruları ile ilişkilendirilerek analiz edilmiş ve kayıt altına alınmıştır.

Araştırmada elde edilen verilerin çözümlenmesinde betimsel analiz tekniği kullanılmıştır. Betimsel analizde elde edilen veriler daha önceden belirlenen temalara göre özetlenir ve yorumlanır (Yıldırım ve Şimşek, 2006). İlk oturum öncesi ve son oturum sonrası gruba yöneltilen sorular dört tema altında gruplandırılmıştır. Bu temalar araştırma sorularıyla da ilişkili olup şu şekildedir; "Farkl11ıklar", "Farklı kültürler", "İnsan değerli oluşu” ve "Farklı kültürden olanla işbirliği ve birlikte yaşayabilme". İlk oturum öncesi ve son oturum sonrası yapılan ve on üç sorunun yöneltildiği grup görüşmelerinden elde edilen verilerin betimsel analizleri, yukarıda belirtilen temalar çerçevesinde ayrı ayrı yapılmış, yorumlanmış ve sonunda da karşılaştırılmıştır.

Araştırmada elde edilen bulgularda, araştırmanın güvenirliğini desteklemek amacıyla öğrencilerin yanıtlarından aynen alıntılar yapılmıştır. Doğrudan alıntılarda çocukların sözleri (Ç, numara) şeklinde gösterilmiştir. Ayrıca, yine araştırmanın güvenirliğini desteklemek amacıyla çocukların ve velilerinin izni ile atölye çalışmaları kamera ve fotoğraf çekimleriyle kayıt altına alınmıştır.

\section{Uygulama Süreci}

Farklı kültürleri tanıma ve birlikte yaşabilme duygu ve düşüncesi geliştirebilme konusunda yedi konu belirlenerek yaratıcı drama yöntemi aşamaları (1sınma/hazırlık, canlandırma, değerlendirme) doğrultusunda yapılandırılmıştır. Uygulama atölyeleri toplam 20 saat olmak üzere 8 oturumda 3 Mart 2013 - 21 Nisan 2013 tarihleri arasında gerçekleştirilmiştir. Oturum başlıkları; “Tanışma-İletişim”, “Japonya”, “Afrika”, "Kızılderili”, “Ötekini fark etme ve empati”, “Ayna (İnsan Değerlidir)”, "Mozaik (işbirliği)”, "Mahallemiz” şeklinde planlanmış ve yaratıcı drama yöntem ve teknikleri kullanılarak uygulamalı bir biçimde gerçekleştirilmiştir. 


\section{Bulgular ve Yorum}

Araştırma kapsamında ulaşılan bulgular, araştırma soruları ile ilişkili olarak belirlenen dört tema doğrultusunda ele alınmıştır. Bu kapsamda araştırmanın bulguları; farklılıklar, farklı kültürler, insan değerli oluşu ve farklı kültürden olanla işbirliği ve birlikte yaşayabilmeye ilişkin bulgular olmak üzere dört alt başlıkta sunulmuştur. İlk oturum öncesi ve son oturum sonrası yapılan grup görüşmelerinden elde edilen bulgular bu başlıklar altında ayrı ayrı değerlendirilmiş olup, sonra da karşılaştırılmıştır.

\section{Birinci Oturum Öncesi Yapılan Görüşmede Elde Edilen Bulgular}

Birinci oturum öncesi çocuklarla on üç soruluk bir görüşme gerçekleştirilmiş. Elde edilen bulgular dört tema altında sunulmuştur.

\section{Farklılıklar Teması}

Çocuklara yöneltilen "Etrafinızdaki insanların sizin gibi olup olmadıkları konusunda neler düşünüyorsunuz?”sorusuna çocukların sekizinin (Ç1, Ç2, Ç3, Ç4, Ç5, Ç8, Ç9, Ç10) "bizim gibi değiller, bizden farkl1lar" yönünde görüş belirttikleri, bir çocuğun da (Ç11) "çoğu farkl1" dediği belirlenmiştir. Dokuz çocuk farklılık olarak fiziksel özelliklere vurgu yapmışlardır. Örneğin Ç4 "Benim gibi değiller, saçları mesela farklı", Ç8 de "Bizim gibi değiller, yüzümüz bile değişik" yanıtını vermişlerdir. iki çocuk ise (Ç6, Ç7) "bilmiyorum" yanıtını vermişlerdir. "Bilmiyorum" yanıtını veren iki çocuk dışında dokuz çocuğun, çevrelerindeki insanların kendilerinden farklı olduklarını düşündükleri ve bu farklılıklarda da daha çok fiziksel özellikler üzerinde durdukları izlenmiştir.

Çocukların "Sizce size benzemeyen (kültür, ırk, cinsiyet, alışkanlık) insanlarla bir arada olmak avantaj olabilir mi?" sorusuna yedi çocuk (Ç2, Ç4, Ç5, Ç8, Ç9, Ç10) “iyi olabilir, onlarla arkadaş olabiliriz” yönünde yanıt vermiştir. Örneğin Ç2 “Onları daha yakından tanımamı, kültürlerini öğrenmemi sağlar” yanıtını vermiştir. Üç çocuk (Ç4, Ç6, Ç7) ise başka kültürlerle arkadaş olunamayacağını söylemişlerdir. Bir çocuk ise (Ç11) bu konuda bir şey bilmediğini söylemiştir. Genel olarak bakıldığında yedi çocuğun olumlu yaklaştı̆̆ı, üç çocuğunda önyargıyla baktıkları söylenebilir.

Çocuklara yöneltilen "Tüm dünya sana benzeyen insanlardan oluşsaydı nasıll bir yer olurdu?"sorusuna verdikleri yanıtlar değerlendirildiğinde, dokuz çocuk (Ç1, Ç2, Ç3, Ç4, Ç6, Ç7, Ç8, Ç9, Ç11) dünyanın kötü ve karışık bir yer olacağını yönünde görüş belirtmişlerdir. Bu konuda Ç3 "Karışık bir yer olurdu, herkes bir birine benzerdi” şeklinde yanıt vermiştir. İki çocuk (Ç5, Ç10) ise iyi bir yer olacağını söylemişlerdir. Çocukların çoğunun farklılığın daha iyi olacağı konusunda eğilim gösterdikleri gözlenmiştir.

Çocukların "Başkalarının yerine kendini koyarak onları anlamaya çalışır mısın?" sorusuna verdikleri yanıtlar değerlendirildiğinde, sekiz çocuğun (Ç2, Ç3, Ç4, Ç6, Ç7, Ç8, Ç9, Ç12) evet yönünde; dört çocuğun da (Ç1, Ç5, Ç10, Ç11) hayır yönünde yanıt verdikleri izlenmiştir. Evet yönünde yanıt verenlerden Ç4 "Mesela İngilizce konuşan birinden İngilizce öğrenerek anlamaya çalışırım" şeklinde, diğerleri de sadece "evet" diyerek görüş belirtmişlerdir. Hayır yönünde görüş belirtenlerden Ç1, Ç10 ve Ç11 sadece "hayır" derken, Ç5 "Hayır, çünkü onlar zaten benim gibi değildir" yanıtını vermiştir. Yanıtlara genel olarak bakıldığında çocukların yarısından çoğunun kendilerini başkalarının yerine koydukları, bununla beraber azımsanamayacak sayıda çocuğun da bunu yapmadığ1 görülmüştür. 
Farklı1ıklar teması bağlamında, çocukların çoğunun çevrelerindeki insanların kendilerinden farklı olduklarını düşünmeleriyle birlikte, bu farklılığın daha çok fiziksel özellikler odaklı olduğu; üç çocuk dışında kalan çocukların farklı özelliklere sahip insanlarla bir arada olmayı avantaj olarak gördükleri söylenebilir. Ayrıca çocukların yarısından fazlasının kendilerini başkalarının yerine koyarak onları anlamaya çalıştıkları görülmüştür.

\section{Farklı Kültürler Teması}

“Dünya üzerinde birçok farklı kültürün varlığını biliyor musun?” sorusuna verdikleri yanıtlar değerlendirildiğinde, yedi çocuğun (Ç3, Ç5, Ç6, Ç7, Ç9, Ç10, Ç11) "evet” yanıtını verdikleri, bir çocuğun (Ç2) "Birçoğunu biliyorum", bir çocuğun da (Ç4) "Bazılarını" şeklinde yanıt verdikleri görülmüştür. İki çocuk da (Ç1, Ç8) bilmediklerini belirtmişlerdir. Yanıtlardan hareketle çocukların birçok kültürü "bildiklerini” düşündükleri görülmektedir.

Çocuklara yöneltilen "Bildiğiniz kültürleri söyler misiniz?” sorusuna, beş çocuk (Ç1, Ç2, Ç3, Ç4, Ç9) Çin, üç çocuk (Ç1, Ç8, Ç10) Japon, üç çocuk (Ç1, Ç8) Afrika, iki çocuk (Ç9, Ç11) zenci (çocukların ifadelerinden aynen alınmıştır), beş çocuk (Ç1, Ç3, Ç5, Ç6, Ç8) Kızılderili yanıtlarını vermiştir. Birer tane de (Ç2) Antarktika, (Ç2) Paris, (Ç4) İstanbul, (Ç4) Kayseri, (Ç3) Amerika, (Ç8) Avustralya, (Ç8) Laz, (Ç8) Kürt, (Ç8) Alman yanıtları verilmiştir. Yanıtlar incelendiğinde çocukların çoğunlukla Çin kültürünü bildiklerini ifade ettikleri, bununla beraber Japon, Kızılderili gibi kültürleri de bildikleri gözlenmiştir. Zenci ve Afrika kültürlerinin de farklı çocuklarca iki ayrı şekilde de ifade edilmesi dikkat çekmiştir. Yine ülkemizden ve dünyadan bazı şehir adlarının da kültür olarak sayıldı̆̆ı gözlenmiştir.

Bu yaş çocuklarında kültür kavramı tam olarak yerleşmemiş olmasına rağmen, farklı kültürler teması altında çocukların birçok kültürü bildiklerini düşündükleri görülmüştür. Çocukların Çin, Japon, Kızılderili, Zenci(çocukların ifadelerinden aynen alınmıştır), Afrika, Amerika, Antarktika gibi örneklerin yanı sıra Paris, İstanbul, Kayseri gibi şehir adlarını da söyledikleri gözlenmiştir.

\section{İnsanın Değerli Oluşu Teması}

“İnsanların değerli canlılar olduğuna inanır mısın?" sorusuna verilen yanıtlar değerlendirildiğinde, dokuz çocuğun (Ç1, Ç2, Ç3, Ç4, Ç6, Ç7, Ç8, Ç9, Ç11) evet yanıtını verdiği, bunların içinden üç çocuğun (Ç1, Ç3, Ç9) "insanların Allah yarattığı için değerli olduklarını" belirttiği izlenmiştir. İki çocuk (Ç5, Ç10) ise hayır demiş, bu çocuklardan biri (Ç5) sadece "Allah'ın değerli olduğunu" söylemiştir. Bir önceki soruyla paralel olarak yine büyük çoğunluk olumlu cevap vermiştir.

"Sizce farklı kültürden insanlar da değerli midir? Neden?" sorusuna verilen yanıtlar değerlendirildiğinde, sekiz çocuğun (Ç2, Ç3, Ç4, Ç5, Ç6, Ç7, Ç8, Ç9) "evet” yönünde görüş belirttikleri, üç çocuğun da (Ç1, Ç10, Ç11) "hayır" yanıtı verdikleri görülmüştür. Evet yanıtı verenlerden (Ç2) "Evet, çünkü onlar da canlı", (Ç4) "Farkl1 özel şeyleri olduğu için değerlidir" şeklinde görüş belirtmişlerdir. Evet diyen çocukların ikisi (Ç3, Ç9) nedenini belirtirken Allah yarattığı için onların da değerli olduğunu söylemişlerdir. Çocuklardan üçü olumsuz yanıt verirken, sekizi olumlu yanıt vermiş; bunların içinden ikisinin de değerli olma özelliğini din ile bağlantılı açıkladıkları gözlenmiştir. 
“Sizin kültürünüzdeki ya da ülkenizdeki insanlar diğerlerinden daha mı değerlidir, yoksa her insan aynı değere mi sahiptir?" sorusuna verilen yanıtlar değerlendirildiğinde, beş çocuğun (Ç2, Ç3, Ç6, Ç7, Ç8) tüm kültürlerin aynı değerde olduğunu söyledikleri; bu konuda, sözgelimi Ç2 "Her insan aynı değere sahiptir, çünkü onlar da insandır” yönünde görüş belirtmiştir. Beş çocuk (Ç1, Ç4, Ç9, Ç10, Ç11) ise, kendi kültürünün daha değerli olduğunu söylemiş; sözgelimi Ç9 "Benim ülkemdekiler daha değerlidir" demiştir. Bir çocuk (Ç5) da "Diğerleri bizden daha değerlidir" diyerek, diğer kültürlerin kendi kültüründen değerli olduğunu söylemiştir. Yanıtlar incelendiğinde çocukların ortak bir yargıda olmaktan uzak oldukları, hatta diğer soruların yanıtları da göz önüne alınırsa en fazla ayrım içinde oldukları sorulardan birisi olduğu gözlenmiştir.

İnsanın değerli oluşu teması altında çocuklara yöneltilen sorulara verilen yanıtlar genel olarak değerlendirildiğinde çocukların ikisi dışında, çoğunluğu insanın değerli olduğunu düşündüklerini, bununla birlikte üç çocuğun Allah yarattığı için insanın değerli olduğunu söyledikleri görülmüştür. Farklı kültürlerden olan insanların da değerli olacağına üç çocuk dişında olumlu yanıt verilmişstir. Kendi kültüründeki insanlar mı daha değerli yoksa her kültürden olan insanlar aynı değere sahip midir? konusunda beş çocuğun her insan değerlidir dediği, ama bunun dışında çocukların birbirlerine göre farklı görüşleri olduğu görülmüştür.

\section{Farklı Kültürrden Olanla İşbirliği ve Birlikte Yaşayabilme Teması}

"Büyük bir projede çalışmak üzere davet edildin ama çalışmak için gittiğinde dünyadan birçok kültürden, dinden, ırktan insanlarla karşılaştın. Bu insanlarla bir arada başarılı bir çalışma yürütebileceğine inanır mısın? Neden?" sorusuna, dokuz çocuğun (Ç1, Ç2, Ç3, Ç6, Ç7, Ç8, Ç9, Ç10, Ç11) evet yanıtını verdiği; sözgelimi Ç3 “Evet, çünkü ben onlara öğretirim, onlar bana öğretir”, Ç9 "Evet, herkesin bilgisinden yararlanılarak başarılı olabiliriz" şeklinde görüş belirttikleri görülmüştür. $\mathrm{Bu}$ olumlu yanıtları çocuklar, (Ç3) "ben onlara öğretirim”, (Ç11) “onlara yardım ederim” gibi cümlelerle desteklemişlerdir. Sadece bir çocuk (Ç5) "Onları anlayamam ve çalışamam” şeklinde olumsuz görüş belirtmiştir. Çocukların büyük bir kısmının beraber bir çalışma yürütebileceklerine inanmakla beraber bu inançlarını kendilerini “öğretici”, "yardımcı” sıfatlarla farklı bir yere koydukları gözlenmiştir.

“İş birliği yapmak hakkında neler düşünüyorsun?” sorusuna verilen yanıtlarda, beş çocuk (Ç1) "Çok güzel”, Ç3 “Zevkli, eğlenceli”, Ç8 “İnsanlar beni işlerine kabul ederse iyi olur diye düşünüyorum”, Ç10 ve Ç11'de “İyi olur” şeklinde olumlu görüş belirtmişlerdir. Dört çocuk (Ç2, Ç6, Ç7, Ç9) işbirliğini yardımlaşma olarak tanımlamış, 2 çocuksa ne demek olduğunu bilmediğini söylemiştir. Çocuklardan beşinin düşüncelerini güzel, zevkli, eğlenceli gibi sıfatlarla destekledikleri, yine dört çocuğun da işbirliği ile yardımlaşma kavramlarını olumlu olarak bir arada kullandığ1 gözlenmiştir. "Herkesle işbirliği yapılır mı?” sorusuna yedi çocuk (Ç1, Ç2, Ç4, Ç5, Ç9, Ç10, Ç11) hayır, üç çocuk (Ç3, Ç6, Ç8) evet, bir çocuk da (Ç7) bazen yanıtlarını vermiştir. Hayır yanıtını veren çocuklardan Ç2 "Yapılamaz, herkes işbirliği yapmak istemez", Ç5 "Yapılamaz, herkes kendi istediğini yapmak ister” şeklinde görüş belirtmişlerdir. Evet yanıtını veren çocuklardan da Ç3 "Evet, işbirliği yapmazsak bir şey inşaat edemeyiz" demiştir. İşbirliği ile ilgili genel olarak olumlu yargıları olan çocukların işbirliği yapılacak kişiler konusunda seçici davranma eğiliminde oldukları ve çoğunluğun olumsuz yanıt verdiği gözlenmiştir.

“Kimlerle işbirliği yapılır?” sorusuna verilen yanıtlarda; üç çocuk (Ç1, Ç3, Ç12) ailemle, üç çocuk $(C ̧ 1$, Ç3, Ç6) arkadaşlarımla, iki çocuk $(C ̧ 1$, Ç3) arkadaş veya komşularla, iki çocuk $(C ̧ 9$, Ç11) 
tanıdıklarla, iki çocuk (Ç2, Ç10) istedikleriyle, bir çocuk (Ç7) iyi olanlarla, bir çocuk (Ç8) insanlarla, bir çocuk (Ç5) erkeklerle (kız öğrencinin cevab1), bir çocuk da (Ç4) önemli kişilerle işbirliği yapılabileceğini söylemiştir. Hemen her çocuğun birbirinden farklı görüşü olduğu ve bununla birlikte çocukların eğilimlerinin daha çok aile, komşu, arkadaş gibi tanıdıkları kişiler üzerinde yoğunlaştığ 1 görülmüştür.

Farklı kültürden olanla işbirliği ve birlikte yaşayabilme teması bağlamında çocukların büyük bir kısmının beraber bir çalışma yürütebileceklerine inanmakla birlikte, kendilerini “öğretici”, "yardımcı" gibi sıfatlarla farklı bir yere koydukları gözlenmiştir. Farklı kültürlerden olanlarla işbirliği yapma konusunda beş çocuğun olumlu görüşlerini "güzel”, "zevkli”, "eğlenceli” gibi olumlu sıfatlar destekledikleri ve dört çocuğunda işbirliği ile yardımlaşma kavramlarını olumlu olarak bir arada kullandıkları görülmüştür.

\section{Son Oturum Sonrası Yapılan Görüşmede Elde Edilen Veriler}

Son oturumun bitiminde, yapılan uygulamaların sonunda grupla bir görüşme yapılmıştır. Bu görüşmede ilk oturumda gruba yöneltilen açık uçlu on beş soru tekrar sorulmuştur. Elde edilen bulgular dört tema altında sunulmuştur.

\section{Farklılıklar Teması}

"Etrafınızdaki insanların sizin gibi olup olmadıkları konusunda neler düşünüyorsunuz?" sorusuna çocukların (Ç1, Ç2, Ç3, Ç4, Ç5, Ç6, Ç7, Ç8, Ç9, Ç10, Ç11, Ç12) tamamı herkesin fark1 özelliklere sahip olabilecekleri yönünde yanıt vermişlerdir. Çocuklar, Ç1 "Herkes farklıdır", Ç8 “Ortak özellikleri olsa da farklılar” örneklerindeki gibi görüş belirtmişlerdir. Bu yanıtlar çocukların, her insanın farklı özellikleri olduğunu, farklı kültürlere ait olma, farklı yaşayış biçimleri geliştirme gibi özelliklerin olduğunu fark ettikleri düşüncesi uyandırmaktadır.

"Sizce size benzemeyen (kültür, ırk, cinsiyet, alışkanlık) insanlarla bir arada olmak avantaj olabilir mi?" sorusuna çocukların on biri de bunun avantaj olabileceğini belirterek, Ç1 "Onları tanıyabiliriz.”, Ç4 “Değişik insan tanırız.”, Ç9 "Bizim de bilgimiz artar, çok şey öğreniriz.” gibi yanıtlar vermişlerdir. Çocukların farklı olan diğerleriyle ilgili beraber bir şeyler yapma, arkadaş olma ya da onları tanıma gibi etkinlikler düşünmelerinin olumlu olduğu düşünülmektedir.

“Tüm dünya sana benzeyen insanlardan oluşsaydı nasıl bir yer olurdu?” sorusuna çocuklar çok sıkıcı olurdu, kötü olurdu, hep aynı şeyler olurdu vb. yanıtlar vermişlerdir. Çocuklar, Ç1 "Çok sıkıcı olurdu”, Ç3 "Hep aynı şeyler olurdu”, örneklerinde olduğu gibi yanıtlar vermişlerdir. Yanıtlardan da anlaşılacağı gibi farklılıkların olmadığ 1 herkesin birbirine benzediği bir dünyanın çocuklar tarafindan yeğlenilmediği görülmüştür.

"Başkalarının yerine kendini koyarak onları anlamaya çalışır mısın?" sorusuna sekiz çocuk (Ç2, Ç3, Ç4, Ç6, Ç7, Ç8, Ç9, Ç12) “evet”, üç çocuk (Ç1, Ç10, Ç11) “bazen”, bir çocuk da (Ç5) bilmiyorum şeklinde yanıt vermiştir. Çocuklardan çalışmaların sonunda olumsuz yanıt gelmemesi ve büyük bir çoğunluğun "evet” şeklinde cevap vermesi empatik davranış geliştirme yönünde olumlu bir adım olarak düşünülmektedir.

Farklılıklar teması bağlamında genel olarak çocuklar, her insanın farklı özelliklerinin olduğunu, insanların ortak özellikleri olsa dahi birbirlerinden farklı olduklarını dile getirmişlerdir. Çocukların tamamı farklı insanlarla bir arada olmayı avantaj olarak değerlendirmişlerdir. 


\section{Farklı Kültürler Teması}

"Dünya üzerinde birçok farklı kültürün varlığını biliyor musun?” sorusuna, bir çocuk (Ç4) "bazılarını”, diğer on çocuk (Ç1, Ç2, Ç3, Ç5, Ç6, Ç7, Ç8, Ç9, Ç10, Ç11, Ç12) ise "evet” yanıtını vermişlerdir. Tüm çocukların araştırma konusuyla paralel olarak farklı kültürlerle ilgili bilgi edindikleri düşünülebilir. En azından kendi kültüründen başka kültürler de olduğunu bildiklerini tüm çocuklar yanıtlarıyla ortaya koymuşlardır.

“Bildiğiniz kültürleri söyler misiniz?” sorusuna çocukların tamamı Kızılderili, Japon, Afrikalı ve Çin kültürlerini belirtmişlerdir. Çocuklardan Ç7 ve Ç9 belirtilen kültürlere ek olarak "Hindistan" yanıtını da vermişlerdir. Yanıtlardan yola çıkılarak çalışmada bahsi geçen tüm kültürlerin yine tüm çocuklarca bilindiği gözlenmektedir.

Farklı kültürler teması bağlamında, bütün çocukların farklı kültürlerle ilgili bilgi edindikleri, en azından kendi kültürlerinden başka kültürlerin de olduğunu bildikleri düşünülebilir. Çalışmada ele alınan tüm kültürler çocuklar tarafından yanıtlarda ortaya konmuş; bu kültürlerle ilgili belirgin özelliklerin çocuklar tarafından rahatlıkla sayıldı̆̆ı gözlenmiştir.

\section{İnsanın Değerli Oluşu Teması}

“İnsanların değerli canlılar olduğuna inanır mısın?" sorusuna on çocuk insanların değerli olduğu yönünde yanıt vermiştir. Bir çocuk (Ç5) ise "Hayır, çünkü Allah değerlidir" yönünde görüş belirtmiştir. Çocukların olumlu yanıt vermeleri insanın değeriyle ilgili olarak insanı değerli görme ve sevme amaçları yönünde olumlu olarak düşünülebileceğini göstermektedir.

"Sence farklı kültürden insanlar da değerli midir? Neden?" sorusuna tüm çocuklar evet demişlerdir. Çocuklar; Ç2 "Değerliler, onların da canı var”, Ç3 "Herkes değerlidir, çünkü insandır”, Ç8 "Evet, onlar da insan" şeklinde yanıtlar vermişlerdir. Sadece daha önce değersiz cevabını veren bir çocuk (Ç1) "değerli, ama bizim kadar değil” cevabını vermiş. Yukarıdaki iki sorunun uzantısı olarak görülebilecek bu soruda, insanı değerli görme ve salt insan olmasından ötürü bu değere sahip olması yönünde düşünce geliştirmeye paralel yanıtlar geldiği gözlenmektedir. Çocuklar sadece kendi kültürlerinden insanları değil tüm insanları değerli görmüşlerdir.

"Senin kültüründeki ya da ülkendeki insanlar diğerlerinden daha mı değerlidir, yoksa her insan aynı değere mi sahiptir?" sorusuna tüm çocuklar her insanın değerli olduğunu belirtmiştir. Çocuklar, Ç1 “Tüm insanlar değerlidir”, Ç4 "Benim ülkemdeki insanlarda, diğer insanlarda değerlidir”, Ç10 "İnsan oldukları için herkes değerlidir” şeklinde yanıtlar vermişlerdir.

İnsanın değerli oluşu teması altında çocukların insanların değerli olduğu konusunda olumlu düşünceleri olduğu; sadece kendi kültüründeki insanların değil tüm insanların değerli olduğunu düşündükleri söylenebilir.

\section{Farklı Kültürden Olanla İşbirliği ve Birlikte Yaşayabilme Teması}

"Büyük bir projede çalışmak üzere davet edildin ama çalışmak için gittiğinde dünyadan birçok kültürden, dinden, ırktan insanlarla karşılaştın. Bu insanlarla bir arada başarılı bir çalışma yürütebileceğine inanır mısın? Neden?" sorusuna çocukların tamamı genel olarak "başarılı bir çalışma ve daha zevkli olabileceği” yönünde düşüncelerini belirtmişlerdir. Bu soruda çocukların doğrudan olumlu yanıt vermeleri araştırmadaki farklı kültürlerden insanlarla işbirliği yapma üzerine olan kısımlardaki etkinliklerden kaynaklı olduğu söylenebilir. 
“İş birliği yapmak hakkında neler düşünüyorsun?” sorusuna dokuz çocuk yanıt vermiş ve hepsi işbirliği yapmanın önemli olduğunu, işlerini kolayca ve hızlıca bitirebileceklerini, işlerinin daha güzel yapılacağını belirtmişler. Bu konuda Ç1 "İş birliğiyle birçok işi yapabiliriz”, Ç5 "İş birliği beraber çalışmak demektir, iyi bir şeydir”, Ç8 “Güzel bir şeydir, hızlıca işlerimizi bitiririz” şeklinde yanıtlar vermişlerdir. Çocukların işbirliğinin sağlayacağı yararları fark etmiş oldukları ve bunu yanıtlarına yansıttıkları gözlenmektedir.

"Herkesle işbirliği yapılır mı?” sorusuna, çocukların neredeyse tamamı herkesle işbirliği yapılamayacağını söylemiş. Tek başına farklı yorumlara açık olan bu sorunun oturumlar sonunda çocuklarda oluşturduğu etkinin yönünü belirlemek için bir sonraki soruyla beraber düşünülmesinin daha yararlı olacağı düşünülmektedir. Zira, herkesle işbirliği yapılamazsa kimlerle yapılabilir, sorusu akıllara gelir ki bununla ilgili çocuklar bir sonraki soruda görüşlerini belirtmişlerdir.

“Kimlerle işbirliği yapılır?” Bu soruda dört çocuk (Ç1, Ç4, Ç10, Ç11)“beraber iş yaptığımız, aynı grupta çalıştı̆̆ımız kişilerle işbirliği yapılabileceğini”, bir çocuk Ç8 "tanımasak da iş birliği yapılabileceğini”, bir çocuk Ç2 "Başkalarını da düşünen iyi niyetlilerle”, bir çocuk Ç12 "Bizimle çalışmak isteyenlerle”, bir çocuk (Ç1) da arkadaşlarla işbirliği yapılabileceğini belirtmiştir. Yanıtlar incelendiğinde çocukların amaç doğrultusunda, hedefe göre iş birliği yapılacak kişileri seçebilecekleri düşünülmektedir.

Farklı kültürden olanla işbirliği ve birlikte yaşayabilme teması bağlamında çocukların işbirliğinin sağlayacağı yararları fark ettikleri söylenebilir. Bununla beraber herkesle işbirliği yapılamayacağını belirten çocukların, amaca göre işbirliği yapılacak kişileri seçebilecekleri görülmüştür. İş birliği yapılacak kişilerde cinsiyet, ırk, inanış, kültür gibi özelliklerin belirtilmemesi de olumlu olarak gözlenmiştir.

\section{Grupla Yapılan Görüşmelerden Elde Edilen Verilerin Karşılaştırılması}

Burada, birinci oturum öncesi ve sekizinci oturum sonunda grupla yapılan görüşmelerden elde edilen veriler karşılaştırılmış, ilk görüşme verileri ile son görüşme verileri arasında bir fark oluşup oluşmadığı belirlenmeye çalışılmıştır.

\section{Farklılıklar Teması}

Her iki görüşme de göz önüne alındığında son görüşmede çocukların kendilerinden daha emin ve net bir şekilde herkesin farklı özellikleri olduğunu belirttikleri gözlenmiştir. Farklı kültürlerden insanlarla bir arada olma konusunda, ilk görüşmeye oranla son görüşmede gözle görülür bir olumlu artış oluştuğu gözlenmiştir. Çocukların farklı insanlarla bir arada olmak, beraber yaşamak gibi kavramlarla olumlu bakış açısı geliştirdikleri düşünülebilir. Özellikle son görüşmeyle beraber çocukların insanlara değer verdikleri ve tereddütlerin, önyargıların olumlu yönde değişim gösterdiği rahatlikla görülebilmektedir.

Çocuklar ilk görüşmede daha çok fiziksel farklılıklara odaklanmışken son görüşmede fiziksel farkl1l1kların kültürel farklılıklara doğru değişim gösterdiği görülüyor. Herkesin farklı özellikleri olduğunu belirtmeleri, insanların farklı farklı düşünceleri olabileceği zeminin oluşması empati becerilerinin gelişmesi açısından önemli bir adım olarak düşünülebilir. 


\section{Farklı Kültürler Teması}

Farklı kültürleri tanıma konusunda iki görüşme sonuçlarının paralellik gösterdiği gözlenmiştir. Bu da farklı kültürleri tanıma açısından çocuklarda olumsuz bir yaklaşım olmadığını düşündürtmektedir. İlk görüşmenin yanıtları incelendiğinde çocukların çoğunlukla Çin kültürünü bildiklerini ifade ettikleri, bununla beraber Japon, Kızılderili, Afrika gibi kültürleri de bildikleri gözlenmiştir. Yine ülkemizden ve dünyadan bazı şehir adlarının da kültür olarak sayıldığı gözlenmiştir. Son görüşmede ise, şehir adlarının kültür olarak söylenmediği, her çocuğun çalışmada yoğun olarak çalışılan kültürleri söyledikleri gözlenmiştir. Çocukların genel olarak çalışılan kültürler bağlamında farklı kültürleri ve farklı kültürlerin temel özelliklerini tanıdıkları izlenmiştir.

\section{İnsanın Değerli Oluşu Teması}

İlk görüşmeye bakıldığında, beş çocuk tüm kültürlerin aynı değerde olduğunu, beş çocuk kendi kültürünün daha değerli olduğunu, bir çocuk da diğer kültürlerin kendi kültüründen değerli olduğunu söylemiş. Yanıtlar incelendiğinde çocukların ortak bir yargıda olmaktan uzak oldukları, hatta diğer soruların cevapları da göz önüne alınırsa en fazla ayrım içinde oldukları sorulardan birisi olduğu gözlenmiştir. Son görüşmeye gelindiğinde ise, tüm çocuklar her insanın değerli olduğunu belirtmiştir. İki görüşme yanıtları bir arada düşünüldüğünde, son görüşmede çocukların tümünün insanları değerli bulması ve farklı kültürleri kendisinden ayırmayarak yanıtlar vermeleri önemli bir değişim olarak nitelendirilebilir.

\section{Farklı Kültürden Olanla İşbirliği ve Birlikte Yaşayabilme Teması}

İlk görüşmede dokuz çocuk farklı kültürlerden insanlarla bir arada başarılı bir çalışma yürütülebileceğini söylerken, üçünün olumsuz yanıt verdiği görülmüştür. Son görüşmede ise, çocukların tamamı genel olarak "başarılı bir çalışma olabileceği” yönünde düşüncelerini belirtmişlerdir. Son görüşmede çocukların yanıtlarını temellendirirken insanların değerliliğine, beraber ortak amaç için çalışmaya ve yardımlaşmaya vurgu yaptıkları görülmüş. Bu vurgunun da beraber yaşama adına olumlu bir fark oluşturduğu düşünülmektedir.

İşbirliği yapmak konusunda, ilk ve son görüşme karşılaştırıldığında, çocukların işbirliğinin toplum yaşamında önemini gösterir nitelikte, işlerin daha hızlı ve nitelikli yapılacağı, paylaşarak, yardımlaşarak daha mutlu olunacağı gibi düşünceler geliştirdikleri görülmektedir. İşbirliği ile ilgili genel olarak olumlu yargıları olan çocukların her iki görüşmede de işbirliği yapılacak kişiler konusunda seçici davranma eğiliminde oldukları gözlenmiştir. Herkesle işbirliği yapılamayacağı görüşünde olan çocukların, "kimlerle işbirliği yapılır?" sorusunda ilk görüşmede çocukların eğilimlerinin daha çok aile, komşu, arkadaş gibi tanıdıkları kişiler üzerinde yoğunlaştığı, son görüşmede çocukların beraber aynı projede, grupta, çalışmada oldukları kişilerden yana eğilim gösterdiği izlenmiştir. Bununla aslında daha önceki üstenci, kendisini ve kendinden olanla beraber olmaya layık gören bakışı bırakarak kültürü değil, ortak amaç için çalışma bakışını geliştirdikleri söylenebilir. 


\section{Sonuç}

Dünya üzerinde yaşayan kültürlerin çocuklar tarafından tanınmasının yaratıcı drama yöntemiyle sağlanmasında, oturumlarda belirlenen kazanımlara ulaşıldığı; çocukların sürece yaratıcı drama yöntemiyle daha istekli dahil oldukları ve kendilerini daha rahat ifade ettikleri görülmüştür. Çocukların farklı kültür- yaşayışlarıyla kendi kültürü-yaşayışı arasındaki karşılaştırmaları yaratıcı drama yöntemi ile yaptıklarında, benzerlik ve farklılıklara kendi yaşantılarıyla daha iyi ulaştıkları izlenmiştir.

Çalışmanın sonunda çocukların kendilerinden daha emin ve net bir şekilde herkesin farklı özellikleri olduğunu belirttikleri, bu farklılıkları sadece fiziksel özellikler temelli değil kültürel farklılıklar temelli betimledikleri, farklı kültürlerden insanlarla bir arada olma konusunda gözle görülür bir olumlu artış oluştuğu gözlenmiştir. Herkesin farklı özellikleri olduğunu belirtmeleri, insanların farklı farklı düşünceleri olabileceği zeminin oluşması empati becerilerinin gelişmesi açısından önemli bir adım olarak düşünülebilir. Çocukların genel olarak çalışılan kültürler bağlamında farklı kültürleri ve farklı kültürlerin temel özelliklerini tanıdıkları izlenmiştir.

Çalışmanın sonunda, tüm çocukların, insanın sadece insan olmasından kaynaklı olarak, her insanın değerli olduğunu belirtmeleri; çocukların tümünün insanları değerli bulması ve farklı kültürleri kendisinden ayırmayarak bu yönde görüş belirtmeleri önemli bir değişim olarak nitelendirilebilir.

İşbirliği ile ilgili genel olarak olumlu yargıları olan çocukların işbirliği yapılacak kişiler konusunda seçici davranma eğiliminde oldukları görülmüştür. Çocukların bu konu ile ilgili düşüncelerine bakıldığında; işbirliğinin toplum yaşamı için önemli olduğunu, işlerin niteliği ve hızının işbirliği ile olumlu anlamda değişebileceğini, beraber yapılan/çalışılan, ortak amaç güdülen projelerde çalışılan kişinin kültürünün belirleyici olmadığı yönünde düşünceler geliştirdikleri gözlenmiştir.

Genel olarak bir kez daha bakılırsa çalışma sonunda, çocukların farklı olanı “öteki” olmaktan çıkardıkları, kültürlere karşı ilgi duydukları, bilgi edinmek istedikleri, beraber de yaşanabileceğine ilişkin olumlu düşünceler geliştirdikleri ve karşı tarafın gereksinim, ilgi ve isteklerini de göz önüne alarak düzenleme yaptıkları ve yapabilecekleri sonucuna varılmıştır.

Çalışmada ulaşılan sonuçlar ışığında; okul öncesi eğitiminde, kültür tanıtımının ağırlıklı olmasının çocuklarda soyut kavramlar öncesi bir alt yapı oluşturması adına etkili olacağı düşünülerek yaratıcı drama yöntemi kullanılarak benzer uygulamalar önerilmektedir.

İlkokul ve ortaokul düzeyinde ise kültür tanıtımları ve beraber yaşama, biz olma bilinci, değerler eğitimi konularına eklemeler yapılarak sosyal bilgiler dersinde, liselerde ise yine genişletilmiş kapsamıyla sosyoloji ve felsefe derslerinde uygulamalar yapılması önerilebilir. 


\section{Kaynakça}

Adıgüzel, Ö. (2013). Eğitimde yaratıcı drama (3.bs.). Ankara: Pegem Akademi Yayınları.

Connolly, W. E. (1995). Kimlik ve farklılık (F. Lekesizalın, Çev.). İstanbul: Ayrıntı Yayınları.

EMIL (2006): Münih Ludwig Maximilian Üniversitesi Kulturlerarası İletişim Enstitusu "Öğretmen Yetişstirme ve Hizmet İçi Eğitiminde Kültürlerarası Öğrenme için Avrupa Modüler Programı (İlkokul Pedagojisi) Projesi” . EMIL sitesinden 01 Haziran 2008 tarihinde erişildi. http://www.emil.ikk.lmu.de/turkish/Brochure-exercises-TR.pdf.

Giddens, A.(2000). Sosyoloji. (1. bs.). Ankara: Ayraç Yayınları.

İlhan Çakır, A. (2010). Panel konuşması. Ö. Adıgüzel (Yay. Haz) 10. Uluslararası eğitimde yaratıcı drama semineri "kültürlerarası etkileşimde yaratıcı drama" içinden. (ss. 19 - 22)Ankara: Natürel Yayınları.

Kitayama, S., Duffy, S., Kawamura, T., \& Larsen, J. T. (2003). Perceiving an object and its context in different cultures A cultural look at new look. Psychological Science, 14(3), 201-206.

Stern, S. L. (1983). Why drama works: A psycholinguistic perspective. J. W., Jr / Richard-Amato, P.A. Oller (Yay. Haz.). Methods that work: A smorgasbord of ideas for language teachers içinden (ss.207-225).

Tdk, Büyük sözlük, www.tdk.gov.tr

Tuğrul B. (2006) Okul öncesi dönemde düşünme becerilerinin gelişmesinde yaratıcı bir süreç olarak drama. Yaratıcı Drama Dergisi. 1(2), 69-70.

Uluç, G. ve Boz, M. (2015). Karşılıklı ötekileştirmeye bir yolculuk: "Otobüs” filmi. TESAM Akademi Dergisi, 2(2), 101-126.

Üskül, Ö. (2003). Bireyciliğe tarihsel baklş. İstanbul: Büke yayınc1lık.

Van de Water, M., McAvoy, M., \& Hunt, K. (2015). Drama and education: performance methodologies for teaching and learning. Routledge.

Yıldırım, A. ve Şimşek, H. (2006). Sosyal bilimlerde nitel araştırma yöntemleri. Ankara: Seçkin Yayınları. 


\section{Ek 1: Örnek Ders Planı (Yedinci Oturum)}

Konu : Toplum Bir Mozaiktir

Grup : Drama yaşantısı olmayan 12 çocuk (7-8 yaş)

Yer : : Bağdaş Özel Ders Bürosu Salonu

Süre : 150 dakika

Yöntem ve Teknikler: Yaratıcı Drama ( Doğaçlama, Rol oynama, Lider Rolde)

Araç-Gereçler: İlgili fotoğraflar, kağıt, boya kalemi, eva süngeri, yapıştırıcı

\section{Kazanımlar:}

Toplumda beraber yaşamak için farklılıkların bir kazanım olduğunu kabul eder.

Farklı özellikteki insanlarla işbirliğine girmeye istekli olur.

\section{Süreç}

\section{A. Hazırlık-Isınma}

\section{Etkinlik}

Her katılımcı masada duran kaseden bir kağıt seçer. Kağıtlarda daha önce çalışılan kültürlere ait tüy, katana, davul gibi simgeler ve bizim kültürümüze ait saz bulunmaktadır. Aynı resimleri seçenler bir araya gelerek grup oluştururlar. Lider bu simgelerin hangi kültürlere ait olduğunu ve o kültürle ilgili neler hatırladıklarını sorar. Kısa sohbetten sonra herkes grubunda kimler olduğunu iyice ezberler. Daha sonra müzik eşliğinde serbest dansa başlanır. Lider müziği kestiğinde en kısa sürede grup üyeleri bir araya gelmeye çalışırlar.

\section{Etkinlik}

Bir sonraki turda her grubun simgesini aldığı kültüre ait bir işaret geliştirmelerini ister. Bu bir kelime ya da ritim olabilir. Ardından her katılımcının gözleri bağlanır. Lider katılımcıların yerlerini değiştirir. Liderin komutu ile katılımcılar grup arkadaşlarını seslerden bulmaya çalışır. Grubunu ilk tamamlayanlar alkışlanır.

\section{Etkinlik}

Lider salonun değişik yerlerine katılımcı sayısına göre 4-5 minder yerleştirir. Sandalye kapmaca oyununa benzer bir oyun oynayacaklarını söyler. Müzik belli aralıklarla sustuğunda minder sayısı azalacaktır, ancak amaç az mindere ne kadar çok kişinin sığabildiğidir. Bu kurala göre oyun oynanır.

\section{Etkinlik}

Katılımcılar liderle beraber çember olurlar. Lider elindeki hulahupu göstererek bu hulahupu tüm grup işaret parmaklarıyla tutarak kaç dakikada yukarıdan aşağıya indirebilirsiniz? Bu kolay bir oyun mu diye sorarak fikirlerini alır ve çemberi belirtilen şekilde katılımcılara bırakır. Katılımcılar çemberi düşürmeden ve sadece işaret parmaklarıyla tutarak aşağı indirmeye çalışırlar. 


\section{Ara Değerlendirme}

- Bu üç oyunu da düşünürsek hangilerinde zorlandınız? Neden?

- Özellikle son oyunu düşünürsek beraber yapılan işlerde işbirliği ya da bir birini dinleme, gözleme önemli midir? Neden?

- Kimlerle iş birliği yapılabilir?

- Evde ailenizle nasıl, ne tür iş birlikleri yapılıyor?

- Başka kimlerle ve ne tür durumlarda iş birliği yapılabilir?

- Toplumda ne gibi iş birliği örnekleri görüyorsunuz?

- İş birliği içinde olan insanların ortak bir amaçları vardır diyebilir miyiz?

- Toplumda yapılacak ortak bir iş, amaç durumunda insanların 1rksal, inançsal, kültürel farkl11ıkları engel midir? Neden?

\section{B. Canlandırma}

\section{Etkinlik}

Lider katılımcılardan her birinin sırtına ZENCI, KIZILDERİLİ, JAPON, ZENGİN, FAKİR, KÖLE, KÖYLÜ, ŞEHIRLİ gibi imlemeler asar. Sırtına yazı asılan kendi sırtında ne yazdığını bilmez ancak arkadaşlarınınkini görür. Lider ressam Xin çıktısını salonun ortasına yerleştirir. Önceden hazırladığı eva süngerlerini küçük mozaikler şeklinde gruba dağıtır ve bunu bir mozaik çalışması gibi düşünebileceklerini belirtir. Mümkün olan en kısa sürede bu çalışmayı tamamlamalarını ister.

\section{Ara Değerlendirme}

- Bu çalışmada zorlandınız mı?

- Tek başınıza yapsaydınız ne gibi zorluklar yaşardınız?

- Çalışma boyunca arkadaşınızın boynunda asılı nitelemeler sizi rahatsız etti mi? Neden?

- Yanımızdaki arkadaşımızı sadece insan olduğu için ve bizimle işbirliği içinde ortak bir amaca doğru çalıştığımızdan değerli görebildik mi?

- Bu çalışmada yaşadığımız olumlulukları günlük yaşama genelleyebilir miyiz? Nasıl?

\section{Etkinlik}

Hazırlanan çalışma sınıf duvarına asılır. Lider bu çalışmanın büyük bir şirketin duvarına asıldığını ve altına da katılan grupların adlarının yazıldığını söyler. Şirket müdürünün ise bu çeşitlikten hoşlanmadığını, müşterilerinin bundan rahatsız olacaklarını düşündüğ̈nü söyler. "Sizler bu tablonun burada kalmasını isteyen çalışanlarsınız. Birazdan müdürünüz gelecek onu ikna edebilecek misiniz” der. Lider, kravat ve gözlük takarak canlandırmaya şirket müdürü olarak dahil olur.

\section{Değerlendirme}

Canlandırma sonunda bu şirketin farklılıklara saygılı bir kurum olduğunu herkese belirten sloganlar hazırlayacakları ve şirket duvarlarına asacakları belirtilir. Asılan sloganlar sırayla tüm kat1lımcilarla gezilir. 